\title{
OPTIMIZATION OF SELF-NANOEMULSIFYING DRUG DELIVERY SYSTEMS OF LEMONGRASS (CYMBOPOGON CITRATUS) ESSENTIAL OIL
}

\author{
TRI UJILESTARI ${ }^{1}$, BAMBANG ARIYADI ${ }^{2}$, RONNY MARTIEN ${ }^{3}$, ZUPRIZAL ${ }^{1}$, NANUNG DANAR DONO ${ }^{1 *}$
}

${ }^{1}$ Department of Animal Nutrition and Feed Science, Faculty of Animal Science, Universitas Gadjah Mada, Yogyakarta, Indonesia, ${ }^{2}$ Department of Animal Production, Faculty of Animal Science, Universitas Gadjah Mada, Yogyakarta, Indonesia, ${ }^{3}$ Department of Pharmaceutics, Faculty of Pharmacy, Universitas Gadjah Mada, Yogyakarta, Indonesia Email: nanungdd@ugm.ac.id

Received: 03 Oct 2018, Revised and Accepted: 19 Nov 2018

\section{ABSTRACT}

Objective: Focus of this study was to optimize and to characterize the self-Nano emulsifying drug delivery system using lemongrass (Cymbopogon citratus) essential oil.

Methods: The optimum formulas were analyzed using a D-Optimal mixture experimental design and performed using a Design Expert ${ }^{\circledR}$ Ver. 7.1.5. Formulation variables which include in the design were: oil component $X_{1}$ (a mixture of Cymbopogon citratus essential oil and virgin coconut oil/VCO), surfactant $X_{2}$ (Tween 80), and co-surfactant (PEG 400), while emulsification time in a sec $\left(Y_{1}\right)$ and transmittance in percent $\left(Y_{2}\right)$ as responses.

Results: The optimum formula for SNEDDS in the current study were: Cymbopogon citratus essential oil (7.147\%), VCO (7.147\%), Tween 80 (71.417\%), and PEG 400 (14.290\%). From the optimizing formula can be shown that the mean of droplet size, polydispersity-index, zeta potential, and viscosity were: $13.17 \pm 0.06 \mathrm{~nm}, 0.17 \pm 0.05,-20.90 \pm 1.47 \mathrm{mV}, 200 \pm 0 \mathrm{mPa} \cdot \mathrm{s}(\mathrm{n}=3)$, respectively. Furthermore, the optimized formula has passed the thermodynamic stability test; meanwhile, transmission electron microscopy displayed spherical shape.

Conclusion: The optimized SNEDDS formula was improving solubility of poorly soluble Cymbopogon citratus essential oil.

Keywords: Cymbopogon citratus, D-optimal mixture design, optimization, self-nanoemulsifying drug delivery system (SNEDDS)

(C) 2019 The Authors. Published by Innovare Academic Sciences Pvt Ltd. This is an open-access article under the CC BY license (http://creativecommons.org/licenses/by/4.0/) DOI: http://dx.doi.org/10.22159/ijap.2019v11i1.30099

\section{INTRODUCTION}

The productivity of broiler chickens can be optimal when the health condition of the gastrointestinal tract is in good condition [1]. The balanced population between pathogenic and beneficial microflora in the gastrointestinal tract plays an important role in nutrient digestion and absorption [2-4]. Escherichia coli, Salmonella typhimurium, and Clostridium perfringens are the three major pathogens in the gut of poultry [5]. Since the high public concerns on antibiotic resistance, the use of antibiotics as growth promoters in the diets of poultry has been banned. There is an urgent need to explore the alternative for antibiotic growth promoters [6].

Essential oils are potential alternatives for an in-feed antibiotic as they have antibacterial properties [7]. Essential oils are classified as phytobiotics that have pharmacological effects [8]. As shown in lemongrass (Cymbopogon citratus) essential oils, this phytobiotic have been found to be effective in inhibiting pathogenic bacteria, such as: Salmonella typhimurium [9], S. enterica [10], Escherichia coli, Staphylococcus aureus, Listeria monocytogenes [11], Klebsiella pneumonia $[12,13]$, and also antifungal activity against Candida albicans [14].

Essential oils are volatile substances, liquid, soluble in lipid and organic solvents [15], and hydrophobic [16]. Essential oils have antibacterial activity but low aqueous solubility [17]. Self-nanoemulsifying drug delivery system (SNEDDS) is one of the effective strategies to improve oral bioavailability [18], solubility [19] and it can control the drug release [20]. The purpose of the formula optimization study is to determine the variable level from which a strong product with high-quality characteristics can be produced [21].

The best formula to combine oils in water is needed to be generated. The present experiments were carried out in order to find the optimum formula of SNEDDS of Cymbopogon citratus essential oil followed by characterization.

\section{MATERIALS AND METHODS}

Preparation of SNEDDS

Firstly, surfactant (Tween 80, Kao Indonesia Chemical, Bekasi, Indonesia), co-surfactant (PEG 400, idCHEM Co., Ltd., Kyunggi, South
Korea), Cymbopogon citratus essential oil (Lansida Group, Yogyakarta, Indonesia) and virgin coconut oil/VCO (Healthy Co, Yogyakarta, Indonesia) were mixed using a magnetic stirrer (IKA® C-MAG HS 7, IKA WORKS Inc., Wilmington, NC, USA). Secondly, ultrasonicator (J. P Selecta, Barcelona, Spain) was utilized to make the SNEDDS formula uniformly disperse. Thirdly, SNEDDS formula was placed into a water bath (Memmert $\mathrm{GmbH}$ and Co. $\mathrm{KG}$, Schwabach, Germany) at $45^{\circ} \mathrm{C}$ for $15 \mathrm{~min}$ [22].

\section{Percent transmittance}

SNEDDS formulations were added with a ratio of 1:50 with distilled water and mixed using vortex for $30 \mathrm{~min}$. The percent transmittance was measured using UV-vis spectrophotometer (Genesys 10, Thermo Scientific Inc, Waltham, MA, USA) at $650 \mathrm{~nm}[21,22]$.

\section{Emulsification time}

The SNEDDS formula was added drop wise to $500 \mathrm{ml}$ of artificial gastric fluid at $37^{\circ} \mathrm{C} \pm 2^{\circ} \mathrm{C}$. The artificial gastric fluid was composed of hydrochloric acid 37\%, NaCl (Merck, Germany), and distilled water. Gentle agitation was provided by a magnetic stirrer (Stuart CB162 Hotplate and Magnetic Stirrer, New Jersey, USA) rotating at $100 \mathrm{rpm}$. The assessment was conducted visually and the time for emulsification was taken [25].

\section{Optimization of SNEDDS}

Along with the formula generated in our previous study [26], SNEDDS were optimized using a D-Optimal mixture experimental designed and performed using a Design Expert ${ }^{\circledR}$ Ver. 7.1.5. software (Stat-Ease Inc., Minneapolis, USA) [27] by selecting the percentage of the oil component X1 (a mixture of VCO and Cymbopogon citratus essential oil), the surfactant X2 (Tween 80), and the co-surfactant (PEG 400) as independent variables, while emulsification time in sec (Y1) and transmittance in percent (Y2) as responses. Data were analyzed by oneway ANOVA at 0.05 levels [28].

\section{Characterization of SNEDDS}

Measurement of droplet size and zeta potential

The droplet size and zeta potential of the optimum formula were determined by dynamic light scattering techniques using a Zeta 
potential/Particle-sizer (Horiba Scientific SZ-100, Horiba, Kyoto, Japan). Liquid SNEDDS $(1 \mathrm{ml})$ was diluted to $100 \mathrm{ml}$ with distilled water and performed in triplicate [29]

\section{Viscosity}

The viscosity of optimum formula was measured by Brookfield viscometer (Brookfield engineering laboratories, Stoughton, MA USA) at $25 \pm 0.5^{\circ} \mathrm{C}$, and at $12 \mathrm{rpm}$. The viscosity of each SNEDDS was performed in triplicate [30].

\section{Thermodynamic stability study}

According to the method of [31], the study of the thermodynamic stability was implemented for optimum formula in three steps:

1. Heating-cooling cycle: The optimum formula was stored at $4^{\circ} \mathrm{C}$ and $45^{\circ} \mathrm{C}$ for $48 \mathrm{~h}$ at each temperature using constant climate chamber bath, it was repeated for 6 cycles in triplicate. The formulation that withstands the heating-cooling cycle was continued to the centrifugation test.

2. Centrifugation test: The optimum formula passed heatingcooling cycle were centrifuged at $5000 \mathrm{rpm}$ for $30 \mathrm{~min}$, observed for any sign of creaming, cracking, or separation phase.

3. Freeze-thaw cycle: The optimum formula passed centrifugation test were exposed at $-21^{\circ} \mathrm{C}$ and $21^{\circ} \mathrm{C}$ for $24 \mathrm{~h}$ at each temperature, centrifuged at $3000 \mathrm{rpm} 5 \mathrm{~min}$, and continued visual observation.

\section{Transmission electron microscopy (TEM)}

The micro-morphology of the optimum formula was observed by TEM Joel JEM-100 CX (Joel, Tokyo, Japan). The SNEDDS was diluted with water (1:1000), a sample drop was stained with $2 \%$ phosphotungstic acid solution, and placed on a copper grid for $30 \mathrm{~s}$ [21].

Table 1: Level of the factors analyzed using D-optimal mixture experimental design

\begin{tabular}{lll}
\hline Factors/Independent variables & Level & How \\
\hline$X_{1}=$ Quantity of Oil (\%) & 14.29 \\
$X_{2}=$ Quantity of Tween 80 (\%) & 60.00 \\
$X_{3}=$ Quantity of PEG 400 (\%) & 71.43 \\
\hline
\end{tabular}

Table 2: Percentage of oil, tween 80, and PEG 400 and observed responses

\begin{tabular}{llllll}
\hline \multirow{2}{*}{ Run } & $\boldsymbol{X}_{\mathbf{1}}$ & $\boldsymbol{X}_{\mathbf{2}}$ & $\boldsymbol{X}_{\mathbf{3}}$ & $\boldsymbol{Y}_{\mathbf{1}}$ & $\boldsymbol{Y}_{\mathbf{2}}$ \\
\cline { 2 - 6 } & $\mathbf{O i l}(\mathbf{\%})$ & Tween 80 (\%) & PEG 400 (\%) & Transmittance (\%) & Emulsification time (s) \\
\hline 1 & 17.737 & 67.973 & 14.290 & 99.600 & 53.480 \\
2 & 14.607 & 66.947 & 18.446 & 99.700 & 51.360 \\
3 & 14.293 & 71.417 & 14.290 & 99.900 & 42.430 \\
4 & 20.000 & 60.005 & 19.995 & 99.800 & 74.400 \\
5 & 20.000 & 60.005 & 19.995 & 99.100 & 85.170 \\
6 & 14.293 & 71.417 & 14.290 & 99.100 & 49.000 \\
7 & 16.764 & 66.028 & 17.208 & 99.800 & 65.000 \\
8 & 20.000 & 65.220 & 14.780 & 99.800 & 70.940 \\
9 & 17.493 & 62.507 & 20.000 & 99.600 & 43.170 \\
10 & 17.454 & 64.168 & 18.378 & 99.800 & 48.030 \\
11 & 14.986 & 65.014 & 20.000 & 99.600 & 53.740 \\
12 & 14.449 & 68.774 & 16.777 & 99.900 & 61.330 \\
13 & 14.986 & 65.014 & 20.000 & 99.500 & 55.640 \\
14 & 20.000 & 62.616 & 17.384 & 99.600 & 57.800 \\
15 & 17.737 & 67.973 & 14.290 & 99.800 & \\
16 & 20.000 & 65.220 & 14.780 & 99.500 & \\
\hline
\end{tabular}

The optimum formula was replicated three times and verified with a single sample t-test with OpenStat® (Industrial Technology Department, Iowa State University, USA). The optimum formula was selected for characterization.

RESULTS AND DISCUSSION

Optimization Formula of SNEDDS

Table 3: The statistical parameter of each response using an experimental design

\begin{tabular}{llll}
\hline Response & $\boldsymbol{F}$ value & Probability $>\boldsymbol{F}$ & Significance \\
\hline$Y=$ Emulsification time & & & Significant \\
Model & 9.32 & 0.0031 & Not significant \\
Lack of fit & 4.66 & 0.0535 & Not significant \\
$Y=$ Transmittance & & Not significant \\
Model & 0.15 & 0.8596 & . \\
Lack of fit & 0.24 & 0.9652 & \\
\hline
\end{tabular}

\section{Emulsification time}

The probability of the model was less than 0.05 , and the lack of fit was more than 0.05 (table 3). This result indicated that the chosen model can describe the relationship between the variables. Fig. 1 showed that the residual is normally distributed around the line and nothing stands out. The relationship between variables was illustrated using a special model cubic (fig. 2). 

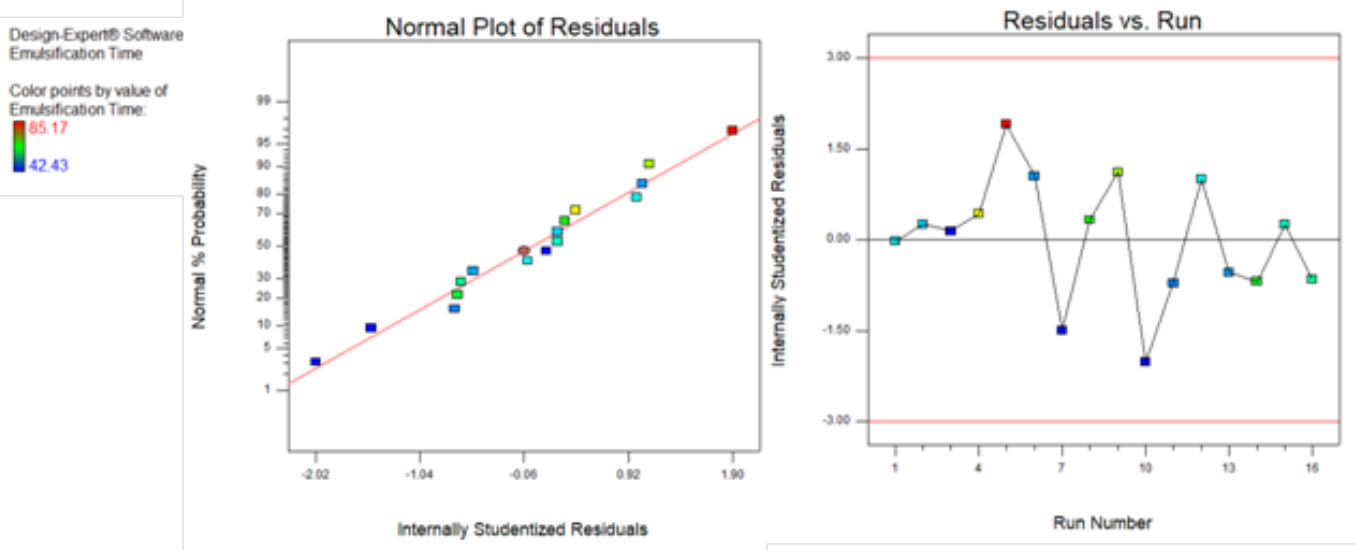

Fig. 1: The normal probability plot residual of emulsification time

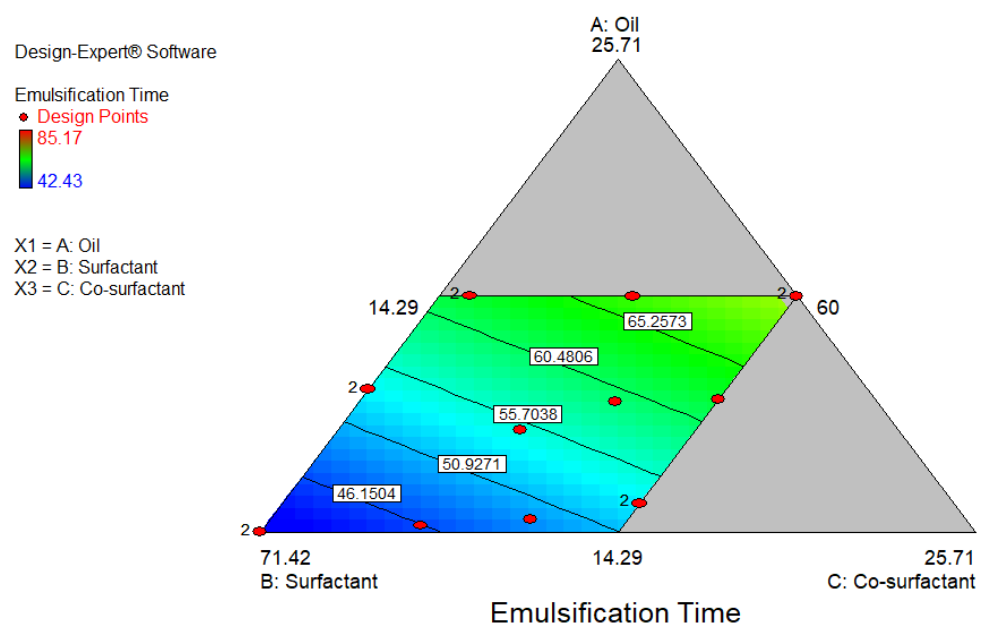

Fig. 2: Special model cubic of emulsification time of the mixture study result

Emulsification time used as a response is a way to determine the ability of surfactant and co-surfactant components to emulsify oil components [32]. Selection of the optimum formula based upon "trading off" from the minimization of emulsification time. Emulsification time is one of the important keys to estimating emulsification efficiency [33].
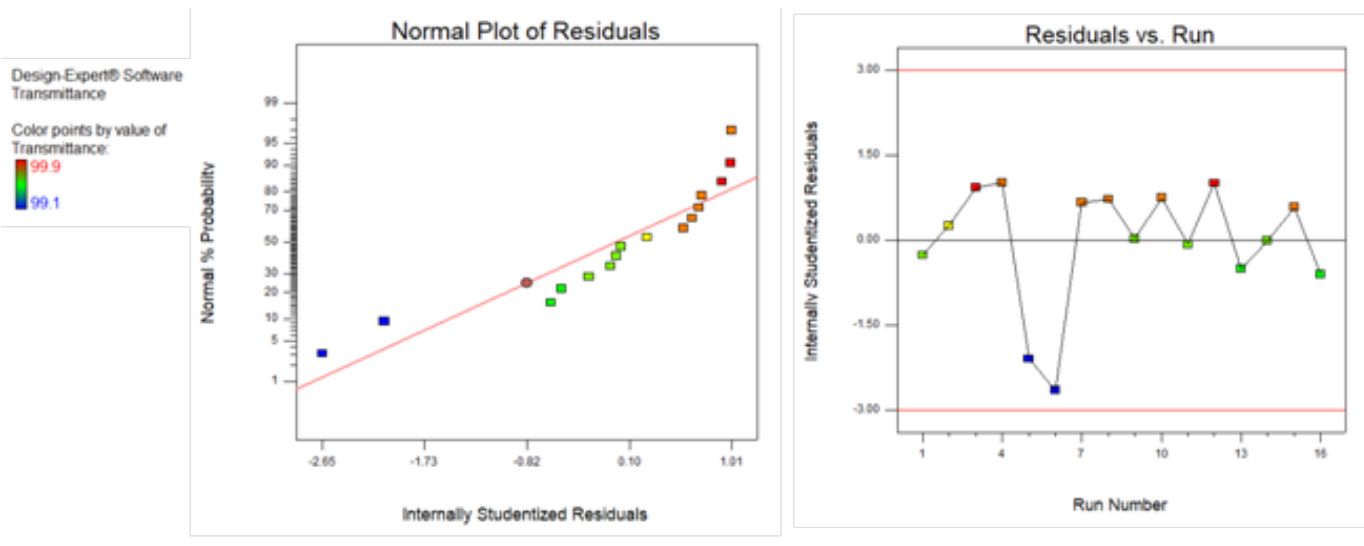

Fig. 3: The normal probability plot residual of transmittance

\section{Percent transmittance}

The probability of the model and the lack of fit were both more than 0.05 (table 3). The data indicated the chosen model can describe the relationship between the variables. Fig. 3 showed that the residual was normally distributed around the line and no one stands out. The relationship between variables was illustrated using a special model cubic (fig. 4). 


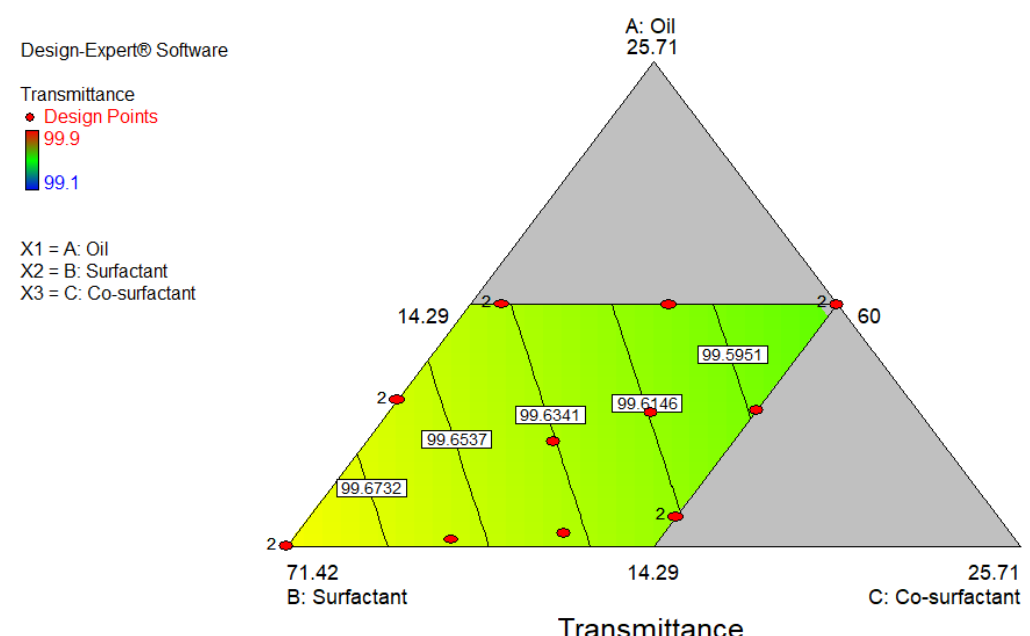

Fig. 4: Special model cubic of transmittance of the mixture study result

The optimization formula aimed to find products that have high-quality characteristics that will be produced [34]. Transmittance must be maximized to produce good quality products. The transmittance value of all treatments is above 99 percent, indicating the efficiency of selfnanoemulsion [35]. A good nanoemulsion has a transmittance value close to 100 percent that indicated a clear nanoemulsion [36].

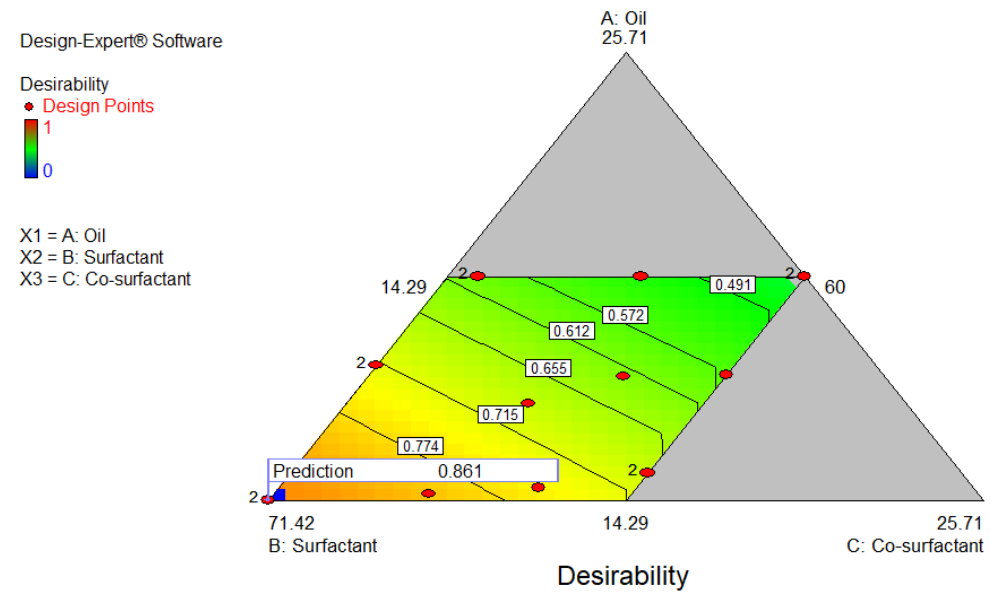

Fig. 5: Desirability

The optimized formula that selected was the one that have a desirability value of close to 1 [37]. Fig. 5 showed the desirability which used to predict the optimum formula. The first solution found through numerical optimization and desirability value was 0.861 . The composition of optimum formula consists of an oil component (14.293\%), Tween 80 (71.417\%), and PEG 400 (14.290\%).

Table 4: Predicted value and actual data of the optimized SNEDDS

\begin{tabular}{llll}
\hline Response & Actual data \pm SD & Predicted value & $P$-value \\
\hline Emulsification time & $42.98 \pm 1.33$ & 41.384 & 0.172 \\
Transmittance & $99.73 \pm 0.12$ & 99.693 & 0.604 \\
\hline
\end{tabular}

*Actual data are mean \pm SD, $n=3$ [SD: Standard deviation], the actual data and predicted value are shown in table 4 . The $P$-value of emulsification time and transmittance was higher than 0.05 , that indicated no significant difference between actual data and the predicted value.

\section{Characterization of SNEDDS}

Table 5: Droplet size, PI, zeta potential, and viscosity of the optimum formulation

\begin{tabular}{lllll}
\hline Replication & Droplet size $(\mathbf{n m})$ & Polydispersity index (PI) & Zeta potential (mV) & Viscosity (mPa $\mathbf{s})$ \\
\hline R1 & 13.2 & 0.219 & -22.6 & 200 \\
R2 & 13.2 & 0.118 & -20.0 & 200 \\
R3 & 13.1 & 0.179 & -20.1 & 200 \\
mean \pm SD & $13.17 \pm 0.06$ & $0.17 \pm 0.05$ & $-20.90 \pm 1.47$ & $200 \pm 0$ \\
\hline
\end{tabular}

* SD: Standard deviation, $\mathrm{n}=3$ 


\section{Droplet size}

The droplet size of nanoemulsion was found to be $13.17 \pm 0.06$ with polydispersity-index (PI) $0.17 \pm 0.05$ (table 5). Droplet size is a crucial factor to evaluate the system of nanoemulsion [38]. Smaller particle size causes better absorption at gastrointestinal tract [39]. The optimum formula shows a PI value lower than 0.5 which indicate uniformity droplet size distribution [40].

\section{Zeta potential}

The zeta potential of the optimum formulation was $-20.90 \pm 1.47 \mathrm{mV}$ as shown in table 5 . The fatty acid content in the formula may cause the negative charge of the zeta potential [41].

\section{Viscosity measurement}

The viscosity of the optimum formulation is $200 \pm 0 \mathrm{mPa} \cdot \mathrm{s}$ (table 5). The concentration of surfactant and carrier oil used in SNEDDS is related to the value of viscosity [18]. The viscosity is directly proportional to the oil concentration [42]

\section{Thermodynamic stability}

The optimum SNEDDS formula did not change visible appearance which showed good stability at various storage conditions (table 6). Nanoemulsion is more stable than an emulsion, SNEDDS that will form nanoemulsion must be thermodynamically stable with the characteristic of not experiencing precipitation, cracking, or creaming [43].

Table 6: Results for thermodynamic stability studies

\begin{tabular}{llll}
\hline Replication & Heating-cooling cycle & Centrifugation test & Freeze-thaw cycle \\
\hline R1 & $\sqrt{ }$ & $\sqrt{ }$ & $\sqrt{ }$ \\
R2 & $\sqrt{ }$ & $\sqrt{ }$ & $\sqrt{ }$ \\
R3 & $\sqrt{ }$ & & \\
\hline
\end{tabular}

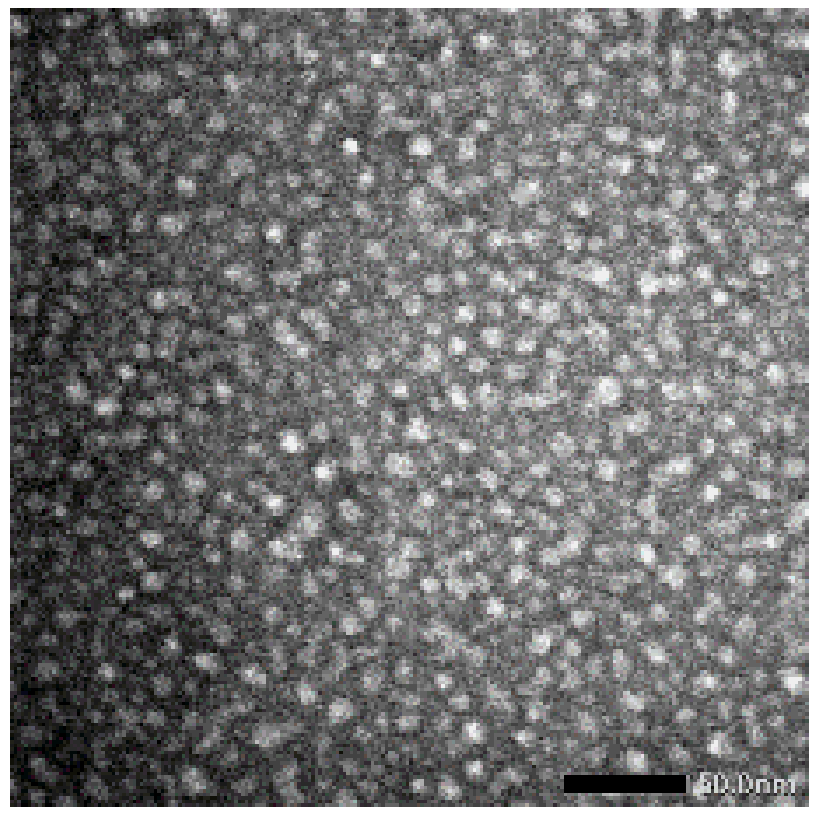

Fig. 6: TEM of optimized SNEDDS formulation $(80,000 \times$; dilution 1000-fold with water)

\section{Transmission electron microscopy (TEM)}

The TEM of the optimum formula is presented in fig. 6. After dilution, all droplets demonstrated spherical shape and almost same size, represented a successful formation of SNEDDS. The TEM of the optimized formulation shows no coalescence signs indicating that the selected formula has good quality [44]

\section{CONCLUSION}

The optimization of Cymbopogon citratus SNEDDS using D-Optimal mixture experimental design was performed. The optimum formula for SNEDDS was a mixture of Tween 80, PEG 400, VCO, and Cymbopogon citratus essential oil at a ratio of 71.417: 14.290: 7.147: 7.147 (\%). From the optimizing formula can be shown that the mean of droplet size, PI, zeta potential, and viscosity were: $13.17 \pm 0.06 \mathrm{~nm}$, $0.17 \pm 0.05,-20.90 \pm 1.47 \mathrm{mV}, 200 \pm 0 \mathrm{mPa} \cdot \mathrm{s}$, respectively. Furthermore, the optimized formula was passed the thermodynamic stability test, meanwhile team displayed spherical shape. The optimized SNEDDS formula was improving solubility of poorly soluble Cymbopogon citratus essential oil.

\section{ACKNOWLEDGMENT}

The authors are thankful to Biopharmaceutics Laboratory, Department of Pharmaceutics, Faculty of Pharmacy, Universitas Gadjah Mada Yogyakarta for an availing facility for these optimization studies. The author expresses gratitude towards DIKTI Ministry of Research, Technology, and Higher Education Indonesia for funding the project under the scheme of PMDSU No. 2050/ UN1/DITLIT/DIT-LIT/IT/2018.

\section{AUTHOR CONTRIBUTIONS}

All the authors have contributed equally

\section{CONFLICT OF INTERESTS}

All the authors declared none

\section{REFERENCES}

1. Sugiharto S. Role of nutraceuticals in gut health and growth performance of poultry. J Saudi Soc Agric Sci 2016;15:99-111.

2. Patterson JA, Burkholder KM. Application of probiotics and probiotics in poultry production. Poult Sci 2003;82:627-31.

3. Amit Romach E, Sklan D, Uni Z. Microflora ecology of the chicken intestine using 168 ribosomal DNA primers. Poult Sci 2004;83:1093-8.

4. Krocko M, Canigova M, Bezekova J, Lavova M, Hascik, Duckova $\mathrm{J}$. Effect of nutrition with propolis and bee pollen supplements on bacteria colonization pattern in the gastrointestinal tract of broiler chickens. Sci Pap Anim Sci Biotechnol 2012;45:63-7.

5. La Ragione RM, Narbad, Gasson MJ, Woodward MJ. In vivo characterization of Lactobacillus johnsonii F19785 for use as a defined competitive exclusion agent against bacterial pathogens in poultry. Lett Appl Microbiol 2004;38:197-205.

6. Hajati H, Rezaei M. The application of prebiotics in poultry production. Int J Poult Sci 2010;9:298-304.

7. Si W, Gong J, Tsao R, Zhou T, Yu H, Poppe C, et al. Antimicrobial activity of essential oils and structurally related synthetic food additives towards selected pathogenic and beneficial gut bacteria. J Appl Microbiol 2006;100;296-305.

8. Grashorn MA. Use of phytobiotics in broiler nutrition-an alternative to infeed antibiotics? J Anim Feed Sci 2010;19:33847.

9. Oussalah M, Caillet S, Saucier L, Lacroix M. Inhibitory effects of selected plant essential oils on the growth of four pathogenic bacteria: $E$ coli 0157:H7, Salmonella typhimurium, Staphylococcus aureus, and Listeria monocytogenes. Food Control 2007;18:414-20.

10. Singh RK, Ebibeni N. Antimicrobial activity of lemongrass (Cymbopogon citratus) oil against microbes of environmental, clinical and food origin. Int Res J Pharm Pharmacol 2011;1:228-36. 
11. Asaolu MF, Oyeyemi OA, Olanloku JO. Chemical compositions, phytochemical constituents and in vitro biological activity of various extracts of Cymbopogon citratus. Pak J Nutr 2009;8:1920-2.

12. Fagbemi JF, Ugoji E, Adenipekun T, Adelowotan O. Evaluation of the antimicrobial properties of unripe banana (Musa sapientum L.), lemongrass (Cymbopogon citratus S.) and turmeric (Curcuma longa L.) on pathogens. Afr J Biotechnol 2009;8:1176-82.

13. Naik MI, Fomda BA, Jaykumar E, Bhat JA. Antibacterial activity of lemongrass (Cymbopogon citratus) oil against some selected pathogenic bacterias. Asian Pac J Trop Med 2010;3:535-8.

14. Juniatik M, Hidayati K, Wulandari FP, Pangestuti N, Munawaroh $\mathrm{N}$, Martien R, et al. Formulation of nanoemulsion mouthwash combination of lemongrass oil (Cymbopogon citratus) and kaffir lime oil (Citrus hystrix) against Candida albicans ATCC 10231. Trad Med J 2017;22:7-15.

15. Bakkali F, Averbeck S, Averbeck D, Idaomar M. Biological effects of essential oils-a review. Food Chem Toxicol 2008;46:446-75.

16. Sanchez Gonzalez L, Vargaz M, Gonzalez Matinez C, Chiralt A, Chafer M. Use of essential oils bioactive edible coatings: a review. Food Eng Rev 2011;3:1-16.

17. Khumpirapang N, Pikulkaew S, Mūllertz A, Rades T, Okonogi S. Self-micro emulsifying drug delivery system and nanoemulsion for enhancing aqueous miscibility of Alpinia galanga oil. PLoS One 2017;12:1-18.

18. Saritha D, Bose PSC, Nagaraju R. Formulation and evaluation of self-emulsifying drug delivery system (SEEDS) of ibuprofen. Int J Pharm Sci Res 2014;5:3511-9.

19. Bansal M, Jamil S. Micellar microparticles: a novel approach to tropical drug delivery system. Int J Appl Pharm 2018;10:1-5.

20. Baskar V, Salim MI, Subramani A, Sruthi, Jawahar A, Shabeer TK. Historic review on the modern herbal nanogel formulation and delivery methods. Int J Pharm Pharm Sci 2018;10:1-10.

21. Basalious EB, Shawky N, Badr Eldin SM. SNEDDS containing bioenhancers for improvement of dissolution and oral absorption of lacidipine. I: development and optimization. Int J Pharm 2010;391:203-11.

22. Lalwani JT, Thakkar VT, Patel HV. Enhancement of solubility and oral bioavailability of ezetimibe by a novel solid self nano emulsifying drug delivery system (SNEDDS). Int J Pharm Pharm Sci 2013;5:513-22.

23. Khan AW, Kotta S, Ansari SH, Sharma RK, Ali J. Selfnanoemulsifying drug delivery system (SNEDDS) of the poorly water-soluble grapefruit flavonoid naringenin: design, characterization, in vitro and in vivo evaluation. Drug Delivery 2015;22:552-61.

24. Winarti L, Suwaldi, Martien R, Hakim L. Formulation of selfnanoemulsifying drug delivery system of bovine serum albumin using HLB (hidrophilic-lypophilic balance) approach. Indonesian J Pharm 2016;27:117-27.

25. Parmar N, Singla N, Amin S, Kohli K. Study of cosurfactant effect on nanoemulsifying area and development of lercadipine loaded (SNEDDS) self nanoemulsifying drug delivery system. Colloids Surf B 2011;86:327-38.

26. Ujilestari T, Dono ND, Ariyadi B, Martien R, Zuprizal. Formulation and characterization of self-nano emulsifying drug delivery systems of lemongrass (Cymbopogon citratus) essential oil. Malays J Fund Appl Sci 2018;14:360-3.

27. Wani A, Sanghani C, Wani S. Formulation, characterization, and in vitro evaluation of novel microemulsion-based spray for topical delivery of isotretinoin. Asian J Pharm Clin Res 2018;11:226-32.
28. Shinkar DM, Aher PS, Kothawade PD, Maru AD. Formulation and in vitro evaluation of fast dissolving tablet of verapamil hydrochloride. Int J Pharm Pharm Sci 2018;10:93-9.

29. Dash RN, Mohammed H, Humaira T, Reddy AV. Solid supersaturatable self-nanoemulsifying drug delivery systems for improved dissolution, absorption and pharmacodynamic effects of glipizide. J Drug Delivery Sci Technol 2015;28:28-36.

30. Ghosh PK, Majithiya RJ, Umrethia ML, Murthy SR. Design and development of microemulsion drug delivery system of aclyclovir for improvement of oral bioavailability. AAPS PharmSciTech 2006;7:172-7.

31. Kaur G, Chandel P, Harikumar SL. Formulation of self nanoemulsifying drug delivery system (SNEDDS) of celecoxib for improvement of oral bioavailability. Pharmacophore 2013;4:120-33.

32. Patel HK, Patel PV, Misan CK, Mehta DS, Patel MB. Development and characterization of liquid and solid self-microemulsifying drug delivery system of tacrolimus. Asian J Pharm 2012;6:204-11.

33. Sahoo SK, Suresh P, Acharya U. Design and development of selfmicroemulsifying drug devilery systems (SMEDDS) of telmisartan for enhancement of in vitro dissolution and oral bioavailability in rabbit. Int J Appl Pharm 2018;10:117-26.

34. Holm R, Jensen IHM. Optimization of self-microemulsifying drug delivery systems (SMEDDS) using a D-optimal design and the desirability function. Drug Dev Ind Pharm 2006;32:1025-32.

35. Gambhire RS, Gujar KN, Gambhire VM. Design and evaluation of self-nanoemulsifying drug delivery systems for nebivolol hydrochloride. Asian J Pharm 2014;8:200-9.

36. Madan JR, Sudarshan B, Kadam VS, Kamal D. Formulation and development of self-microemulsifying drug delivery system of pioglitazone hydrochloride. Asian J Pharm 2014;8:27-35.

37. Beg S, Swain S, Singh HP, Patra CN, Rao MEB. Development, optimization, and characterization of solid selfnanoemulsifying drug delivery systems of valsartan using porous carriers. AAPS PharmSciTech 2012;13:1416-27.

38. Jeevana JB, Sreelakhmi K. Design, and evaluation of selfnanoemulsifying drug delivery system of flutamide. J Young Pharm 2011;3:4-8.

39. Subramanian P, Siddalingam R. Self-nanoemulsifying drug delivery systems of poorly soluble drug dutasteride: formulation and in vitro characterization. J Appl Pharm Sci 2017;7:11-2.

40. Chavda H, Patel J, Chavada G, Dave S, Patel A, Patel C. Selfnanoemulifying powder of isotretinoin: Preparation and characterization. J Powder Technol 2013;1-9. http://dx.doi.org/10.1155/2013/108569

41. Bandivadekar M, Pancholi S, Kaul-ghanekar R, Choudhari A, Koppikar S. Single non-ionic surfactant based selfnanoemulsifying drug delivery systems: formulation, characterization, cytotoxicity and permeability enhancement study. Drug Dev Ind Pharm 2013;39:696-703.

42. Rahman MA, Iqbal Z, Hussain A. Formulation optimization and in vitro characterization of sertraline loaded selfnanoemulsifying drug delivery system (SNEDDS) for oral administration. J Pharm Invest 2012;42:191-202.

43. Kassem AA, Mohsen AM, Ahmed RS, Essam TM. Selfnanoemulsifying drug delivery system (SNEDDS) with enhanced solubilization of nystatin for treatment of oral candidiasis: design, optimization, in vitro and in vivo evaluation. J Mol Liq 2016;218:219-32.

44. Bahloul B, Lassoued MA, Seguin J, Lai-Kuen R, Dhotel H, Sfar S, Mignet N. Self-nanoemulsifying drug delivery system developed by the HLB-RSM approach: characterization by transmission electron microscopy and pharmacokinetic study. Int J Pharm 2015;487:56-63. 